\title{
SENAM TAI CHI DALAM UPAYA MENURUNKAN KADAR KOLESTEROL PADA LANSIA DI DUSUN SIDOMULYO DESA REJOAGUNG KECAMATAN PLOSO KABUPATEN JOMBANG
}

\author{
(Senam Tai Chi In Order To Reduce Cholesterol Levels In Elderly In Sidomulyo \\ Desa Rejoagung Ploso Jombang)
}

\author{
Heni Maryati \\ Sekolah Tinggi Ilmu Kesehatan Pemkab Jombang \\ nie.maryati@gmail.com
}

\begin{abstract}
ABSTRAK
Kadar kolesterol darah yang tinggi berakibat serius terhadap kesehatan individu. Semakin tinggi nilai kolesterol darah maka semakin tinggi resiko terjadinya penyakit jantung dan pembuluh darah. Bagi mereka yang memiliki kolesterol tinggi, olahraga dan diet menjadi kunci utama penurunan kolesterol agar tidak berpengaruh pada fungsi jantung. Salah satu jenis olah raga yang mampu menurunkan kolesterol dalam darah adalah senam taichi. Meski gerakannya halus dan lambat, sebuah studi menyatakan bahwa gerakan taichi dapat menurunkan total kolesterol sebesar 7\%, dimana LDL kolesterol turun sebesar 12\% hingga 15\% sedangkan kolesterol baik meningkat hingga mencapai 7\%. Mengingat Penyakit pembuluh darah merupakan 10 besar penyakit di Wilayah Kerja Puskesmas Bawangan termasuk di Dusun Sidomulyo dimana hasil studi pendahuluan dengan pemeriksaan kadar kolesterol darah mayoritas kadar kolesterol darah > 200 mg/dl terutama pada lansia maka dilakukan pengabdian masyarakat Senan tai chi dalam upaya menurunkan kadar kolesterol.. Pelaksanaan di rumah kasun Dusun Sidomulyo tanggal 27 Februari 2018 mulai pukul 09.00 12.00 WIB. Peserta adalah penderita hiperkolesterolemia di Dusun Sidomulyo Desa Rejoagung Kecamatan Ploso Kabupaten Jombang sejumlah 31 orang dari yang di undang sebanyak 34 orang dimana $91 \%$ peserta datang dengan antusias. Kegiatan diawali dengan perkenalan, memberikan informasi tentang hiperkolesterolemia dan komplikasinya. Memperkenalkan tentang senam taichi, memperagakan gerakan senam taichi diiringi musik dengan alunan pelan, mengajak semua penderita melakukan senam taichi, dan terakhir meminta peserta mempraktekkan senam taichi. Memberikan kesempatan bertanya dan menyampaikan kesimpulan tentang senam taichi. Dengan bekal kemampuan senam taichi peserta bisa mempraktekkan sendiri di rumah atau bersama dan menjadi agenda kegiatan rutin seperti di Posyandu lansia sehingga bisa menurunkan kadar kolesterol darah agar tidak sampai terjadi komplikasi yang berakibat terjadinya kematian.
\end{abstract}

Kata kunci : Senam tai chi, Kolesterol, Lansia

\section{PENDAHULUAN}

Hiperkolesterolemia menjadi masalah kesehatan di negara maju maupun negara bekembang. Kadar kolesterol darah yang tinggi berakibat serius terhadap kesehatan individu. Semakin tinggi nilai kolesterol darah maka semakin tinggi resiko terjadinya penyakit jantung dan pembuluh darah . Hiperkolesterolemia adalah suatu kondisi dimana meningkatnya konsentrasi kolesterol dalam darah melebihi nilai normal yang terbukti mengganggu dan mengubah struktur pembuluh darah yang mengakibatkan gangguan fungsi endotel yang menyebabkan lesi, plak, oklusi serta emboli sehingga pembuluh darah menyempit dan aliran darah tidak lancar. Inilah yang menjadi salah satu faktor resiko penyakit jantung dan pembuluh darah merupakan penyebab kematian nomor satu di dunia (Syahmani dan Sudarsih, 2010). Ada banyak hal yang menjadi penyebab atau pemicu timbulnya kolesterol tinggi dalam darah. Penyebab meningkatnnya kadar kolesterol paling banyak disebabkan oleh asupan makanan yang banyak mengandung lemak jenuh, 
pola hidup yang tidak sehat dan seimbang, gaya hidup yang salah dan kebiasaan buruk yang menjadi rutinitas sehari-hari (Anwar.dkk, 1996). Tidak bisa dipungkiri bahwa olahraga adalah kegiatan yang menyehatkan dan melindungi Anda dari berbagai macam penyakit. Bagi mereka yang memiliki kolesterol tinggi, olahraga dan diet menjadi kunci utama penurunan kolesterol agar tidak berpengaruh pada fungsi jantung. Banyak literatur yang menyebutkan bahwa olahraga aerobik seperti berlari, berenang, dan bersepeda misalnya adalah olahraga yang paling berkhasiat dalam rangka penurunan kolesterol. Jika tidak terlalu suka dengan olahraga aerobik, tentu Anda masih memiliki beberapa pilihan lain. Olahraga jenis apapun akan membantu menurunkan kadar kolesterol dalam darah (Mamat,2010). Terlebih, akan lebih baik jika Anda mampu mengombinasikan beberapa diantaranya. Salah satu jenis olah raga yang mampu menurunkan kolesterol dalam darah dalah senam taichi. Taichi yang awalnya adalah seni bela diri kini telah menjadi olahraga populer bagi mereka yang tidak bisa terlalu bebas bergerak karena sakit atau usia lanjut. Gerakan Taichi yang lembut dan perlahan sangat cocok bagi mereka yang ingin melakukan olahraga dan melatih jantung tanpa harus bergerak terlalu keras. Meski gerakannya halus dan lambat, sebuah studi menyatakan bahwa gerakan taichi dapat menurunkan total kolesterol sebesar 7\%, dimana LDL kolesterol turun sebesar 12\% hingga 15\% sedangkan kolesterol baik meningkat hingga mencapai $7 \%$. Olahraga apapun akan sangat membantu Anda menjaga ketahanan tubuh. Kunci untuk dapat merasakan efek baik olahraga adalah dengan melakukannya secara rutin. 40 menit olahraga yang disertai pemanasan dan pendinginan, 3 hingga 4 kali seminggu adalah frekuensi yang tepat untuk kesehatan jantung Anda.
Mengingat Penyakit pembuluh darah merupakan 10 besar penyakit di Wilayah Kerja Puskesmas Bawangan termasuk di Dusun Sidomulyo dimana hasil studi pendahuluan dengan pemeriksaan kadar kolesterol darah mayoritas kadar kolesterol darah >200 mg/dl terutama pada lansia maka penulis tertaris untuk melakukan pengabdian masyarakat Senan Tai Chi dalam upaya menurunkan kadar kolesterol pada lansia di Dusun Sidomulyo Desa Rejoagung Kecamatan Ploso Kabupaten Jombang .

\section{METODE PELAKSANAAN}

Kegiatan pengabdian masyarakat ini untuk deteksi dini komplikasi tingginya kadar kolesterol darah pada penderita penderita hiperkolesterolemia dengan mengajarkan senam taichi yang bisa menurunkan kadar kolesterol darah. Kegiatan diawali dengan perkenalan, memberikan informasi tentang hiperkolesterolemia dan komplikasinya. Memperkenalkan tentang senam taichi, memperagakan gerakan senam taichi diringi musik dengan alunan pelan, mengajak semua penderita melakukan senam taichi, dan terakhir meminta peserta mempraktekkan senam taichi.

\section{HASIL DAN PEMBAHASAN}

Kegiatan pengabdian masyarakat
ini diharapakan meningkatkan
pengetahuan
hiperkolestterolemia tentang deteksi dini komplikasi hiperkolesterolemia. Kehadiran peserta menunjukkan tingkat kepedulian terhadap perannya sebagai peserta untuk membantu mencegah terjadinya komplikasi hiperkolesterolemia yang di derita sehingga tujuan pengabdian masyarakat tentang komplikasi hiperkolesterolemia tercapai dimana peserta mau melakukan senam taichi guna menurunkan kadar kolesterol darahnya sehingga tidak sampai menimbulkan komplikasi, sehingga yang secara langsung bisa 
menurunkan

komplikasi

hiperkolesterolemia dan menurunkan angka kematian. Kegiatan senam taichi dalam rangka menurunkan kader kolesterol darah dilaksanakan di balai rumah kasun Dusun Sidomulyo Desa Rejoagung Kecamatan Ploso Kabupaten Jombang pada tanggal 27 Februari 2018 mulai pukul 09.00 -12.00 WIB. Peserta adalah para penderita hiperkolesterolemia di Dusun Sidomulyo sejumlah 31 orang dari yang di undang sebanyak 34 orang dimana $91 \%$ peserta datang dengan antusias. Kegiatan pertama di mulai dengan mempersiapkan daftar hadir, berita acara dan kelengkapan lainnya untuk pelaksanaan, Melakukan pengabdian masyarakat yang diawali dengan perkenalan, memberikan informasi tentang hiperkolesterolemia dan komplikasinya. Memperkenalkan tentang senam taichi, memperagakan gerakan senam taichi, mengajak semua penderita melakukan senam taichi, dan terakhir meminta penderita hiperkolesterolemia mempraktekkan senam taichi. Memberikan kesempatan bertanya dan menyampaikan kesimpulan tentang senam taichi dan menganjurkan penderita untuk mempraktekkan senam taichi sendiri di rumah .Dengan bekal kemampuan senam taichi peserta bisa melakukan mandiri di rumah atau bersama dan menjadi agenda kegiatan rutin seperti di Posyandu lansia sehingga bisa menurunkan kadar kolesterol darah agar tidak sampai terjadi komplikasi yang bisa berakibat terjadinya kematian. menjadi agenda rutin masyarakat.

\section{KESIMPULAN}

Dengan adanya pengabdian masyarakat ini akan menambah pengetahuan, penderita hiperkolesterolemia tentang deteksi komplikasi tingginya kadar kolesterol darah yang mereka derita.Dengan bekal kemampuan melakukan senam taichi secara mandiri atau dilakukan secara bersama -sama dengan peserta lain di harapakan bisa digunakan untuk menurunkan kadar kolesterol darah agar tidak sampai terjadi komplikasi yang bisa berakibat terjadinya kematian

\section{SARAN}

1. Bidan desa menindaklanjuti pelaksanaan senam taichi ini sebagai agenda kegiatan rutin misalnya di lakukan saat posyandu lansia serta memotivasi para penderita hiperkolesterolemia untuk menerapkan senam taichi secara rutin di rumah

2. Pihak desa dan puskesmas menfasilitasi pelaksanaan senam taichi

3. Diadakan penelitian tentang efektifitas senam taichi dalam menurunkan kadar kolesterol darah pada penderita hiperkolesterolemia

DAFTAR PUSTAKA

Anwar,dkk.1996. Pengantar Praktikum Kimia Organik. Depdikbud. Jakarta

Mamat.2010. Factor -Faktor yang berhubungan dengan kadar kolesterol HDL pada keluarga di Indonesia. Tesis. IKM. Fakultas Kesehatan Masyarakat. Universitas Indonesia. Jakarta

Syahmani dan Sudarsih.2010. Penuntun Praktikum Biokimia. FKIP.Unlam.Banjarmasin 